\title{
DEGRADAÇÃO DE PASTAGENS EM REGIÕES DE CERRADO
}

\author{
Pasture degradation in savanna's regions
}

\author{
Antônio José Peron ${ }^{1}$, Antônio Ricardo Evangelista²
}

\begin{abstract}
RESUMO
A degradação das pastagens tem sido um grande problema para a pecuária brasileira, desenvolvida basicamente em pasto. Estima-se que $80 \%$ dos 50 a 60 milhões de hectares de pastagens cultivadas no Brasil Central encontram-se em algum estado de degradação, ou seja, em processo evolutivo de perda de vigor, sem possibilidade de recuperação natural e incapazes de sustentar os níveis de produção e qualidade exigido pelos animais, bem como de superar os efeitos nocivos de pragas, doenças e plantas invasoras. Essa degradação é consequiência de vários fatores que atuam isoladamente ou em conjunto, como, preparo incorreto do solo, escolha errada da espécie forrageira, uso de sementes de baixa qualidade, má formação inicial, manejo inadequado e, principalmente, em razão da não-reposição dos nutrientes perdidos no processo produtivo, por exportação no corpo dos animais, erosão, lixiviação e volatilização ao longo dos anos. A persistência desse processo culmina com a degradação do solo e dos recursos naturais, com prejuízos irrecuperáveis para toda a sociedade.
\end{abstract}

Termos para indexação: Pastagens, degradação, forragicultura.

\begin{abstract}
Pasture degradation has been a great problem for Brazilian livestock breeding, developed basically from grassland. It is estimated that $80 \%$ out of the 50 to 60 million hectares of grassland grown in Central Brazil lie in some degradation status, namely, in a evolutive process of vigor loss, with no possibility of natural recovery and incapable of supporting yield and quality demanded by the animals as well as of overcoming the harmful effects of pest insects, diseases and weeds. That degradation is a consequence of a number of factors, which act singly or jointly, such as incorrect soil tillage, wrong choice of the forage species, use of low quality seeds and poor initial establishment, inadequate management and chiefly due to the non-replacement of the nutrients lost in the productive process by export into the animals' body, erosion, leaching and volatilization along the years. The persistence of these processes peaks with degradation of soil and of the natural resources with irrecoverable damages to all the society.
\end{abstract}

Index terms: Pastures, degradation, forage culture.

(Recebido para publicação em 30 de junho de 2003 e aprovado em 22 de setembro de 2003)

\section{INTRODUÇÃO}

Na década de 1970, houve uma grande expansão da produção pecuária devida, especialmente, ao baixo valor das terras, às ofertas de crédito e ao surgimento de espécies forrageiras com alta capacidade de adaptação ao clima e à baixa fertilidade dos solos. Atualmente, a atividade de pecuária bovina é responsável por mais de $44 \%$ do rebanho bovino nacional, e esse rebanho tem nas pastagens cultivadas sua principal fonte alimentar (MOREIRA e ASSAD, 1997). No entanto, a degradação das pastagens tem sido um grande problema para a pecuária brasileira, por ser essa desenvolvida basicamente em pastos, afetando diretamente a sustentabilidade do sistema produtivo.

Estima-se que $80 \%$ das pastagens cultivadas no Brasil Central, responsáveis por mais de $55 \%$ da produção de carne nacional, encontrem-se em degradação.
Isso afeta diretamente a sustentabilidade da pecuária. Considerando-se apenas a fase de engorda de bovinos, a produtividade de carne de uma pastagem degradada pode ser seis vezes inferior ao de uma pastagem recuperada ou em bom estado de manutenção (MACEDO et al., 2000).

Apesar disso, existe um número ainda reduzido de pecuaristas que estão recuperando as pastagens de suas propriedades. Uma pastagem degradada é aquela que está em processo evolutivo de perda de vigor e produtividade forrageira, sem possibilidade de recuperação natural, tornando-se incapaz de sustentar os níveis de produção e qualidade exigidos pelos animais, bem como o de superar os efeitos nocivos de pragas, doenças e plantas invasoras. Persistindo esse processo, poderá haver uma degradação total do solo e dos recursos naturais, com prejuízos irrecuperáveis para toda sociedade (MACEDO et al., 1993; MACEDO, 1995).

\footnotetext{
1. Zootecnista, Docente da Universidade Federal do Tocantins/UFT - Doutorando em Zootecnia na Universidade Federal de Lavras/UFLA - Caixa Postal 37 37200-000 - Lavras, MG.

2. Engenheiro Agrônomo, Docente do Departamento de Zootecnia da UFLA, aricardo@ufla.br
} 


\section{Principais fatores responsáveis pela degrada- ção das pastagens}

São vários os fatores que podem levar à degradação das pastagens, entre eles, a escolha incorreta da espécie forrageira, a má formação inicial, a falta de adubação de manutenção e o manejo inadequado da pastagem. A falha em alguns desses fatores pode acelerar o processo de degradação.

\section{Escolha da espécie forrageira}

Em princípio, pode-se dizer que para cada tipo de solo, nível tecnológico utilizado e produtividade pótencial esperada, existe uma espécie ou cultivar mais indicada.

De acordo com Kichel et al. (1999), a escolha da melhor espécie forrageira deve ser precedida de um diagnóstico, por meio do qual se considera o histórico da área, conhecendo-se o início da utilização da mesma, a espécie em uso, a predominância de plantas invasoras e o potencial de pragas e doenças existente no local. O tipo de solo e suas condições, bem como as condições climáticas da região, também são fatores importantes a se considerar.
Para a região dos Cerrados do Brasil Central, local onde se concentra a maior parte do rebanho bovino nacional, pode-se selecionar espécies como as apresentadas na Tabela 1, de acordo com as condições edafoclimáticas existentes.

\section{Formação de pastagens}

É importante conhecer a qualidade das sementes disponíveis no mercado, bem como a quantidade a ser utilizada no plantio. O uso de sementes sem conhecimento do seu valor cultural pode conduzir ao risco de semear uma quantidade abaixo do ideal, podendo, na maioria das vezes, conduzir a uma baixa densidade de plantas por área, o que possibilita a competição por ervas daninhas.

O tamanho das sementes é outro fator importante, podendo ocorrer variações entre espécies, e até mesmo dentro de uma mesma espécie. Sementes maiores, por acumular mais reservas, tendem a se sobressair mais, em detrimento de sementes menores, em condições adversas, ou seja, maiores profundidades.

O número aproximado de sementes, por grama, de algumas espécies forrageiras, bem como as quantidades sugeridas de sementes no plantio são apresentados na Tabela 2.

TABELA 1 - Exemplos de algumas espécies de gramíneas forrageiras recomendadas para a região dos cerrados, considerando-se algumas condições edafoclimáticas.

\begin{tabular}{lc}
\hline \multicolumn{1}{c}{ Condições Gerais } & Espécies Indicadas \\
\hline $\begin{array}{l}\text { Solos úmidos (mal drenados) e/ou temporariamente úmidos, com baixa fertili- } \\
\text { dade ou solos de baixa fertilidade com alto grau de erodibilidade }\end{array}$ & $\begin{array}{l}\text { Brachiaria humidicola, } \\
\text { Brachiaria dictyoneura }\end{array}$ \\
\hline Solos de baixa fertilidade e/ou rasos (com cascalho) & Andropogon gayanus \\
\hline $\begin{array}{l}\text { Solos de baixa a média fertilidade, bem drenados, em regiões de baixa incidên- } \\
\text { cia de cigarrinhas }\end{array}$ & $\begin{array}{c}\text { Brachiaria decumbens, } \\
\text { Andropogon gayanus }\end{array}$ \\
\hline $\begin{array}{l}\text { Solos de média a alta fertilidade, bem drenados, em regiões com ou sem cigarri- } \\
\text { nhas }\end{array}$ & Brachiaria brizantha \\
\hline $\begin{array}{l}\text { Solos de média a alta fertilidade, profundos, bem drenados } \\
\text { Solos úmidos (mal drenados), profundos, de média a alta fertilidade }\end{array}$ & $\begin{array}{c}\text { Panicum maximum, } \\
\text { Cynodon purpureum, }\end{array}$ \\
\hline
\end{tabular}

Fonte: Kichel et al. (1999). 
Em áreas com preparo de solo inadequado, a taxa de semeadura deve ser bastante aumentada. Da mesma forma, semeaduras superficiais ou tardias devem ser feitas com taxas mais elevadas.

A correção e a adubação do solo também devem ser feitas, considerando-se a baixa fertilidade natural dos solos dos Cerrados, sendo importante a aplicação de calagem e de adubação de plantio, principalmente a fonte de fósforo, com base nas análises de solo e nas exigências nutricionais da forrageira a ser implantada. A calagem e a adubação melhoram a fertilidade do solo, promovem melhor estabelecimento da pastagem, aumentando a sua densidade, proporcionando, consequientemente, maior cobertura do solo, protegendo-o da erosão. A presença dos animais confere ao sistema aspectos próprios de extração e reciclagem dos nutrientes; num sistema de pastagem perene e pastejo contínuo, por exemplo, a reciclagem de nutrientes pode ser da ordem de 70 a $90 \%$ (MACEDO, 1995). Nessa situação, poderá influir na manutenção das pastagens; daí, dizer que as doses de fertilizantes necessária na implantação é sempre maior que na sua manutenção.

O preparo do solo deve proporcionar um bom estabelecimento das forrageiras, com equipamento apropriado e na época recomendada para reduzir custos, pois serviços de desmatamento e preparo do solo são os que mais oneram a formação de pastagens.

Zimmer e Miranda (1994) destacam a importância de se efetuarem pelo menos duas gradagens com grade pesada ou uma aração seguida de gradagem com a grade niveladora, visando a reduzir a rebrota das plantas perenes de cerrado. Para se reduzirem os custos de formação, o plantio da pastagem pode ser precedido de um ou dois cultivos anuais, ou ainda ser feito um plantio conjunto da pastagem com o arroz, milho ou outras culturas, quando for o caso. Esse plantio conjunto promove um melhor preparo do solo, evitando o rebrote do cerrado e ainda proporcionando algum resíduo de fertilizante para a pastagem, reduzindo o custo de formação.

TABELA 2 - Número aproximado de sementes por grama de várias espécies de forrageiras tropicais e sugestão de taxas de semeadura a serem feitas no início do período chuvoso, em áreas que receberam preparo adequado de solo.

\begin{tabular}{lcc}
\hline \multicolumn{1}{c}{ Espécies Forrageiras } & $\begin{array}{c}\text { Número Aproximado } \\
\text { de Sementes/Grama }\end{array}$ & $\begin{array}{c}\text { Taxa Semeadura } \\
\text { (kg/ha SPV })\end{array}$ \\
\hline Andropogon gayanus & 360 & 2,50 \\
\hline Brachiaria brizantha & 150 & 2,80 \\
\hline Brachiaria decumbens & 200 & 1,80 \\
\hline Brachiaria humidicola & 270 & 2,50 \\
\hline Brachiaria ruziziensis & 230 & 2,00 \\
\hline Paspalum guenoarum & 300 & 1,50 \\
\hline Paspalum notatum cv. Pensacola & 610 & 1,50 \\
\hline Panicum maximum cv. Tanzânia & 960 & 1,60 \\
\hline Panicum maximum cv. Colonião & 780 & 1,60 \\
\hline Panicum maximum cv. Tobiatã & 610 & 2,50 \\
\hline Setaria anceps cv. Kazungula & 1490 & 1,50 \\
\hline
\end{tabular}

Fonte: Souza (1993).

*SPV = Sementes puras viáveis 
O método de plantio também é um fator interessante. Pode ser realizado a lanço (aéreo ou terrestre) sobre a superfície do solo ou em linha, com o uso de semeadeira ou adubadeira; segundo Zimmer e Miranda (1994), a época ideal para a semeadura de pastagens na região dos cerrados é entre os meses de novembro e janeiro. Esses autores acrescentam que quando se utiliza grade, essa deve trabalhar parcial ou totalmente fechada, uma vez que, além de incorporar a semente ao solo, auxilia no acabamento do preparo do solo e na incorporação do adubo, eliminando plântulas de espécies indesejáveis. O uso do rolo compactador proporciona maior contato da semente como o solo, favorecendo maior germinação de plantas por área.

As plantas invasoras concorrem com as forrageiras por nutrientes, espaço físico, luz e umidade. Um aumento de 10 a $20 \%$ na quantidade de sementes por hectare favorece a competição inicial das forrageiras, garantindo uma boa formação da pastagem (ZIMMER e MIRANDA, 1994).

Em áreas com grande incidência de plantas invasoras, é necessário o controle químico, associados também a práticas manuais e mecânicas.

O controle de formigas, cupins, cigarrinha e lagartas pode ser necessário em regiões onde o grau de infestação é grande. Assim, quando o nível de infestação for significativo, deve ser controlado com inseticidas e formicidas (COSTA, 1983). Se não forem controladas, essas pragas podem comprometer a formação e a persistência das pastagens, causando degradação.

Em pastagens já estabelecidas, a praga que causa maiores danos na região de cerrados são as cigarrinhas (Deois incompleta, Deois schach, Deois flavopicta, Zulia entreriana, Aeneolamia selecta selecta), podendo causar redução de até $90 \%$ da produção, em pastagens de Brachiaria decumbens. Embora possam ser feitos controles químicos e biológicos para essa praga, a melhor alternativa é a de usar espécies de forrageiras com algum nível de resistência (VALÉRIO e KOLLER, 1993), como descritos na Tabela 3.

O pastejo de uniformização contribui para a boa formação da pastagem. Inicia-se, geralmente, de 60 a 100 dias após a germinação ou antes da emissão da inflorescência, com alta lotação. Devem-se utilizar, de preferência, animais jovens, por curto período de tempo, entre dez e trinta dias. Com o uso de animais jovens, evita-se a compactação maior do solo, uma vez que esse foi recém-trabalhado (ARANGO GUTIERREZ, 1990). A finalidade desse manejo é diminuir a competição entre plantas e eliminar a maior parte das gemas apicais, reduzindo-se, assim, a produção de sementes e a translocação de nutrientes para essas, estimulando a emissão de novos perfilhos e a mais rápida cobertura do solo (VIEIRA e KICHEL, 1995). A não-realização dessa prática conduz a crescimento excessivo, com formação de touceiras nas forrageiras de hábito de crescimento cespitoso, as quais tendem a se acamar com o vento e presença de animais. Isso pode acarretar a necessidade de roçagens mecânicas ou, o que é pior, o uso de fogo para a eliminação de macegas ou palhadas.

\section{Fogo}

As pastagens naturais de cerrados têm sido sujeitas a fogo em sua evolução, apresentando adaptação natural à queima. Nas pastagens cultivadas, tanto quanto possível, o fogo deve ser evitado. O uso contínuo do fogo tem como consequiência a exposição do solo ao impacto das gotas de chuva, aumentando a compactação e a erosão, além de interromper gradualmente o ciclo de retorno da matéria orgânica, diminuindo a capacidade de troca de cátions, a retenção de água, a perda de nutrientes do sistema, principalmente N, S e K (UHL e BUSCHBACHER, 1988; BONO et al., 1996), o que favorece o surgimento de plantas invasoras e acelera o processo de degradação das pastagens.

TABELA 3 - Grau de susceptibilidade de algumas forrageiras às cigarrinhas das pastagens.

\begin{tabular}{cl}
\hline $\begin{array}{c}\text { Grau de Susceptibilidade às } \\
\text { Cigarrinhas das Pastagens }\end{array}$ & Espécies \\
\hline Susceptíveis & Brachiaria decumbens, Brachiaria ruziziensis \\
\hline Tolerantes & Panicum maximum cvs. Tanzânia e Mombaça \\
\hline Resistentes & $\begin{array}{l}\text { Brachiaria brizantha, Brachiaria humidicola, Andropogon gayanus, } \\
\text { Setaria anceps, Cynodon plectostachyus }\end{array}$ \\
\hline
\end{tabular}

Fonte: Valério e Koller (1993)

Ciênc. agrotec., Lavras, v. 28, n. 3, p. 655-661, maio/jun., 2004 


\section{Manejo da pastagem}

Segundo Nascimento Júnior et al. (1994), o principal efeito provocado pelos animais na pastagem é o da desfolhação, que reduz a área foliar, com conseqüências sobre os carboidratos de reserva, perfilhamento, crescimento das raízes e de novas folhas, comprometendo o seu desenvolvimento.

A redução na produção de matéria seca reduz de maneira drástica o sistema radicular, perfilhamento, expansão de folhas nova e reservas de carboidratos nas raízes (CORSI e NASCIMENTO JÚNIOR, 1994).

O pastejo malconduzido, aliado ao estresse ambiental, também leva à degradação da pastagem.

Em experimentos com Panicum maximum, cv. Colonião, Mella (1993) observou que altas pressões de pastejo, associadas a curtos períodos de descanso, 28 dias, levaram à degradação da pastagem em apenas 3 anos. A alta pressão de pastejo somente seria sustentável com um longo período de descanso. Já as menores pressões foram mais favoráveis à persistência da pastagem.

Um intervalo de descanso muito prolongado, entretanto, em alguns casos, pode implicar numa menor produção de forragem. Na consorciação de Panicum maximum cv. Colonião com um coquetel de leguminosas, Mella (1993) observou que o conteúdo de leguminosas foi satisfatório, com a conjugação de períodos de descanso curto e com pressão de pastejo leve, que é um sistema de manejo mais próximo do contínuo, num período de três anos.

\section{Reposição de nutrientes perdidos no sistema}

Uma das principais causas da degradação das pastagens é a redução da fertilidade do solo, em razão de nutrientes perdidos no processo produtivo, na constituição do corpo dos animais, na erosão, na lixiviação e volatilização, na fixação em argila e matéria orgânica e nos acúmulos de malhadores (MARTINS et al., 1996, citado por KICHEL et al., 1999), como pode ser visto na Tabela 4.

Euclides et al. (1997) estudaram a recuperação de pastagens de Panicum maximum cvs. Colonião, Tobiatã e Tanzânia, Brachiaria decumbens cv. Basilisk e Brachiaria brizantha cv. Marandú. Os autores testaram os seguintes níveis de adubação: (NF1) - 1,5 t/ha de calcário e $400 \mathrm{~kg} / \mathrm{ha}$ da fórmula $0-16-18$ e $50 \mathrm{~kg} / \mathrm{ha}$ de FTE; (NF2) - $3 \mathrm{t} / \mathrm{ha}, 800 \mathrm{~kg} / \mathrm{ha}$ e $50 \mathrm{~kg} / \mathrm{ha}$ dos mesmos corretivos e fertilizantes aplicados no primeiro ano e sem adubação nos anos seguintes. Pelos resultados obtidos, constatou-se que a produtividade, para todas as gramíneas e em qualquer nível de fertilização, decresceu linearmente do primeiro para o terceiro ano. Assim, a produtividade caiu de $670 \mathrm{de} \mathrm{kg} / \mathrm{ha} / \mathrm{ano} \mathrm{PV}$ para 435 $\mathrm{kg} / \mathrm{ha} / \mathrm{ano}$ de PV no tratamento NF2; e de 445 $\mathrm{kg} / \mathrm{ha} / \mathrm{ano}$ de PV para $325 \mathrm{~kg} / \mathrm{ha} / \mathrm{ano}$ de $\mathrm{PV}$ para o tratamento NF1, ou seja, um decréscimo na produtividade de $35 \%$ e $25 \%$, respectivamente, em três anos, utilizando-se pastejo contínuo, com pressão de pastejo controlada. Essa redução de produtividade deve-se ao fato de que não foi realizada adubação de manutenção, principalmente com $\mathrm{N}$.

TABELA 4 - Perdas de nutrientes ocorridos anualmente em uma pastagem.

\begin{tabular}{lccc}
\hline \multirow{2}{*}{ Discriminação } & \multicolumn{2}{c}{ Nutrientes (\%) } \\
\cline { 2 - 4 } & $\mathbf{N}$ & $\mathbf{P}$ & $\mathbf{K}$ \\
\hline Retido no corpo do animal & 9 & 10 & 13 \\
\hline Acúmulo nos malhadores & 11 & 12 & 3 \\
\hline Erosão superficial & 3 & 15 & 0 \\
\hline Volatilização & 15 & 0 & 0 \\
\hline Fixação em argila e matéria orgânica & 0 & 19 & 0 \\
\hline Lixiviação & 5 & 0 & 17 \\
\hline Total de perdas & 43 & 56 & \\
\hline
\end{tabular}

Fonte: Martins et al. (1996) citado por Kichel et al. (1999). 
Uma vez equilibrados os outros nutrientes, a maior resposta em produção de forragem é atribuída à adição de fertilizantes nitrogenados. Entretanto, esse elemento é um dos mais caros por unidade entre os macronutrientes utilizados nas pastagens. Perdas de nitrogênio por lixiviação e volatilização podem representar a principal forma de saída do elemento do sistema de uma pastagem de gramíneas, e vir a se constituir na principal causa de degradação das mesmas, caso não haja reposição desse nutriente por fonte externa (MONTEIRO e WERNER, 1989, citado por KICHEL et al., 1999).

Até $95 \%$ do nitrogênio ingerido pelo animal são retornados ao solo via urina e fezes, grande parte do qual pode ser retirado do sistema por volatilização e lixiviação (WHITEHEAD, 1990). As excreções são, por outro lado, distribuídas ao acaso nas áreas de pastejo, em especial sob pastejo contínuo, com concentrações nos malhadores, pontos de água ou sombra. Em pastejo rotativo, há certa uniformização dessa distribuição, ainda assim restrita a não mais do que um terço da área pastejada (AFZAL e ADAMS, 1992).

A desintegração das excreções é variável, podendo levar até nove meses para ocorrer (COSTA et al., 1992). Deve-se considerar ainda que ao redor do bolo fecal cria-se uma área de rejeição ao pastejo pelos animais, a qual acarreta uma diminuição da área total de pastagem disponível. A melhor forma de desintegração é feita por besouros coprófagos, que enterram o bolo fecal em cerca de dois dias (MIRANDA et al., 1990). Os besouros coprófagos, nativos da América do Sul, evoluíram em condições de pouca disponibilidade de esterco, sem habilidade para suportar o grande aporte de fezes bovinas. A introdução do Onthophagus gazella pelo Centro Nacional de Pesquisa de Gado de Corte, da Empresa Brasileira de Pesquisa Agropecuária, Campo Grande, MS (BIANCHIN et al., 1992), uma espécie mais prolífera do que as nativas, tem ajudado na solução desse problema. Por meio de resultados de experimentação, verifica-se o grande potencial desse besouro no enterrio de fezes bovinas e o conseqüente reaproveitamento de nutrientes, tais como $\mathrm{N}$ e $\mathrm{P}$ pelas plantas (MIRANDA et al., 1998).

Outros elementos, como o P e o K, são igualmente importantes para a manutenção estável de uma pastagem (MACEDO et al., 1993). Tais elementos devem ser repostos, seguindo-se criteriosa análise de solo, cuja reposição só pode ser feita pela adição de fertilizantes. Em relação ao P, pode utilizar-se o potencial de micorrizas no aproveitamento de fontes de menor solubilidade, tais como os fosfatos de rocha, o que, no en- tanto, não elimina a necessidade de adubação fosfatada com fósforo solúvel.

A análise do solo é de fundamental importância, tanto para a implantação de uma pastagem como para uma cultura anual, pois possibilita o conhecimento do grau de deficiência ou desequilíbrio de nutrientes essenciais ao desenvolvimento de cada cultura e, com isso, monitora-se a fertilidade do solo e, em conseqüência, há a possibilidade de recomendações racionais de adubo de manutenção.

\section{CONSIDERAÇÕES FINAIS}

A degradação das pastagens tem afetado diretamente a sustentabilidade da pecuária nacional, além de diminuir o valor das terras e atrasar a idade de abate dos animais. Mesmo assim, existe um número reduzido de pecuaristas recuperando pastagens de suas propriedades, ou mesmo preocupados com esse problema. A adoção de medidas com o preparo correto do solo, a escolha da espécie forrageira adequada para o local, o uso de sementes qualificadas e na quantidade certa, o manejo correto das pastagens, observando a pressão de pastejo e um período de descanso adequado e também adubações de manutenção, seriam suficientes para resolver o problema. Persistindo o processo de degradação, com certeza haverá prejuízos irrecuperáveis para os recursos naturais.

\section{REFERÊNCIAS BIBLIOGRÁFICAS}

AFZAL, M.; ADAMS, W. A. Heterogenoity of soil mineral nitrogen in pasture grazed by cattle. Soil Science Americam Journal, Madson, v. 56, p. 11601166, 1992.

ARANGO GUTIERREZ, J. I. Sistema de taxas de lotação fixas na avaliação de pastagens: avaliação metodológica. 1990. 92 f. Tese (Doutorado) - Universidade Federal de Viçosa, Viçosa, 1990.

BIANCHIN, I.; HONER, M. R.; GOMES, A. Controle integrado da mosca-dos-chifres na região Centro-Oeste. Hora Veterinária, Porto Alegre, v. 11, n. 65, p. 43-46, jan./fev. 1992.

BONO, J. M.; MACEDO, M. C. M.; EUCLIDES, V. P. B. Alterações nas propriedades químicas de um latossolo sob pastagem cultivada, após queima. In: SIMPÓSIO SOBRE CERRADO, 8.; INTERNATIONAL SYMPOSIUM ON TROPICAL SAVANAS, 1., 1996, Brasília, DF. Anais... Planaltina: EMBRAPA-CPAC, 1996. p. 341-345. 
CORSI, M.; NASCIMENTO JÚNIOR, D. Princípios de fisiologia e morfologia de plantas forrageiras aplicados no manejo de pastagens. In: PEIXOTO, A. M.; MOURA, J. C.; FARIA, V. P. Pastagens, fundamentos da exploração racional. 2. ed. Piracicaba: FEALQ, 1994. p. 25-47.

COSTA, J. M. da. Pragas das pastagens no Estado da Bahia e meios de controle. Salvador, BA: EPABA, 1983. (EMBRAPA, Circular Técnico, 6).

COSTA, M. J. R. P. da; RODRIGUES, L. R. de A.; SOUZA, R. C. de; MORYAMA, C. M. Desintegration of dung pats in coastcross pastures grazed by holtein cows. In: INTERNATIONAL SCIENTIFIC CONFERENCE IFOAM. Organic Agriculture, a key to a sound developement an a sustainable environment. São Paulo: IFOAM, 1992. p. 226-232.

EUCLIDES, V. P. B.; MACEDO, M. C. M.; OLIVEIRA, M. P. Desempenho animal em pastagens de gramíneas recuperadas com diferentes níveis de fertilização. In: REUNIÃO ANUAL DA SOCIEDADE BRASILEIRA DE ZOOTECNIA, 34., 1997, Juiz de Fora, MG. Anais... Juiz de Fora: SBZ, 1997. v. 2, p. 201-203.

KICHEL, A. N.; MIRANDA, C. H. B.; ZIMMER, A. H. Degradação de pastagens e produção de bovinos de corte com a integração agricultura x pecuária. In: SIMPOSIO DE PRODUÇÃO DE GADO DE CORTE, 1., 1999, Viçosa. Anais... Viçosa: UFV, 1999. p. 201-234.

MACEDO, M. C. M. Pastagens nos ecossistemas de cerrados: pesquisas para o desenvolvimento sustentável. In: SIMPÓSIO SOBRE PASTAGENS NOS ECOSSISTEMAS BRASILEIRAS, 1995, Brasília, DF. Anais... Brasília: SBZ, 1995. p. 28-62.

MACEDO, M. C. M.; EUCLIDES, V. P. B.; OLIVEIRA, M. P. Seasonal changes in the chemical composition of cultivated tropical grasses in the savanas of Brazil. In: INTERNATIONAL GRASSLAND CONGRESS, 17., 1993, Palmerston North. Proceedings... Palmerston North: New Zealand Grassland Association, 1993. v. 3, p. 2000-2002.

MACEDO, M. C. M.; KICHEL, A. N.; ZIMMER, A. H. Degradação e alternativas de recuperação e renovação de pastagens. Campo Grande: EMBRAPACNPGC, 2000. 4 p. (Comunicado Técnico, 62).
MELLA, S. C. Manejo como fator de recuperação de pastagens. In: ENCONTRO SOBRE RECUPERAÇÃO DE PASTAGENS, 1., 1993, Nova Odessa. Anais... Nova Odessa: IZ, 1993. p. 61-78.

MIRANDA, C. H. B.; NASCIMENTO, Y. A.; BIANCHIN, I. Desenvolvimento integrado de controle de nematódeos e a mosca-dos-chifres na região dos Cerrados: fase 3, potencial de Onthophagus gazella no enterrio de fezes bovinas. Campo Grande: EMBRAPACNPGC, 1990. 5 p.

MIRANDA, C. H. B.; SANTOS, J. C. C.; BIACHIN, I. Contribuição de Ontophagus gazella à melhoria da fertilidade do solo pelo enterrio de massa fecal bovina fresca: 1. estudo em casa de vegetação. Revista da Sociedade Brasileira de Zootecnia, Viçosa, v. 27, n. 4, p. 681-685, 1998.

MOREIRA, L.; ASSAD, E. D. Segmentação e classificação supervisionada para identificar pastagens degradadas. Planaltina: EMBRAPA-CPAC, 1997.

NASCIMENTO JÚNIOR, D. do; QUEIROZ, D. S.; SANTOS, M. V. F. dos. Degradação de pastagens, critérios para avaliação. In: SIMPÓSIO SOBRE MANEJO DA PASTAGEM, 11., 1994, Piracicaba. Anais... Piracicaba: FEALQ, 1994. p. 107-151.

SOUZA, F. H. D. de. O papel das sementes no estabelecimento e na formação de pastagens. Campo Grande: EMBRAPA-CNPGC, 1993. 111 p.

UHL, C.; BUSCHBACHER, R. Queimada: o corte que atrai. Ciência Hoje, Rio de Janeiro, v. 7, n. 40, p. 2428, 1988.

VALÉRIO, J. R.; KOLLER, W. W. Proposição para manejo integrado das cigarrinhas das pastagens. Campo Grande: EMBRAPA-CNPGC, 1993. 46 p.

VIEIRA, J. M.; KICHEL, A. N. Estabelecimento e recuperação de pastagens de Panicum maximum. In: SIMPÓSIO SOBRE MANEJO DE PASTAGENS, 12., 1995, Piracicaba. Anais... Piracicaba: FEALQ, 1995. p. 147-96.

WHITEHEAD, D. C. Grassland nitrogen. Wallinford: CAB International, 1990. 397 p.

ZIMMER, A. H.; MIRANDA, C. H. B. Aspectos práticos ligados à formação de pastagens. Revista dos Criadores, São Paulo, v. 64, n. 776, p. 30-46, 1994. 